\title{
APLICAÇÃO DA CERTIFICAÇAO LEEDTM NO BRASIL: CONTRIBUIÇÃO AO ENTENDIMENTO COM BASE EM DOIS ESTUDOS DE CASOS
}

\author{
Application of LEEDTM in Brazil: contribution to the understanding in two case studies \\ VANESSA GOMES DA SILVA ARQ DR. \\ ANDREA FONSECA PARDINI, ENG. MSC.
}

Professora Associada do Departamento de Arquitetura e Construção, Faculdade de Engenharia Civil, Arquitetura e Urbanismo, Universidade Estadual de Campinas. Pesquisadora associada ao Mascaro Center for Sustainable Innovation e Professora visitante no Department of Chemical and Petroleum Engineering, University of Pittsburgh, Pittsburgh - PA, United States of America, vangomes@fec.unicamp.br

Mestre em Engenharia Civil pela Faculdade de Engenharia Civil, Arquitetura e Urbanismo, Universidade Estadual de Campinas, Campinas - SP, Brasil.

\begin{abstract}
The quest for higher sustainability standards in the Civil Construction Industry is still incipient. This research aims to study the application of the LEEDTM certification to Brazilian buildings, understanding the restrictions for its use in a reality different from the original American reference, and disseminate the analyzed results of two national case studies to put the debate in perspective. Obtained results confirmed that (1) obtaining a LEEDTM certificate is not an easy task and in Brazil it means jumping from complete lack of reference to follow North American standards; and (2) even in developed civil construction centers in Brazil, the market is not yet prepared for international green certification. There are huge obstacles to be overcome but certification opens discussion on matters never approached before in Brazil. Though limited, introduction of building certification in the Brazilian market opens discussion on subjects never treated before. Certifications, voluntary schemes and other market pull instruments play a fundamental role in market transformation for sustainability, but depend on a previous foundation regarding $P \& D$ and knowledge and technology transfer. The quest for certification in itself should be avoided. Otherwise, it may put at risk the valuable contribution building certification can bring to market transformation.
\end{abstract}

Keywords: Sustainable Buildings; LEED Certification; Building Projects; Brazil 


\section{APLICAÇÃO DA CERTIFICAÇAO LEEDTM NO BRASIL: CONTRIBUIÇÃO AO ENTENDIMENTO COM BASE EM DOIS ESTUDOS DE CASOS}

\section{Introdução}

Faz algum tempo que a atenção pública está voltada para problemas sócio-ambientais. A preocupação não só com a vida no planeta, mas com a qualidade de vida emergiu como foco de governantes, mídia e comunidades acadêmicas. Entretanto, no setor da indústria da construção civil este movimento ainda é incipiente. A tendência da construção sustentável está emergindo lentamente e conquistando construtores e clientes. Começa-se a perceber uma ligação entre valor de mercado e as construções sustentáveis (DAVIES, 2005), recebendo este assunto mais atenção e um especial interesse de toda a cadeia produtiva.

Os edifícios mais sustentáveis, além de contribuírem para o meio ambiente e potencialmente poderem apresentar custos operacionais e de manutenção inferiores aos edifícios tradicionais (DAVIS LANGDON, 2007; KATS, 2003; KATS, 2006), desempenham papéis sociais junto à comunidade, seja pelo seu aspecto cultural ou de saúde e junto à região e/ou município no qual ele está inserido, sendo o agente promotor da valorização da área e da geração de empregos diretos e indiretos. No entanto, existe uma grande lacuna - de entendimento e conhecimento - entre a indústria sustentável e as entidades (pessoas ou organizações) responsáveis pela viabilidade de um empreendimento (DAVIES, 2005).

Edifícios são tipicamente investimentos de longo prazo, de magnitude significativa, e os modelos de valoração existentes tendem a contabilizar os custos e benefícios da fase de aquisição do produto (NORNES, 2005). Enxergar uma edificação ou um empreendimento de maneira não convencional, por meio do conceito de seu ciclo de vida, onde o ponto de partida antecede à elaboração dos projetos e o término se estende além do término das obras, é um dos primeiros passos na busca da sustentabilidade e pode ser considerado quebra de paradigma. Sustentabilidade é um conceito de longo prazo, porém com viabilidade atualmente medida numa contrastante visão de curto prazo, com base em variações da análise de custo inicial. Várias das estratégias/tecnologias que, de fato, têm custo inicial maior, pagam-se ao longo de um horizonte de tempo que ainda pode ser bastante razoável, apesar de acima do usualmente aceito e praticado na construção civil (MELAVER; PHYLLIS, 2009). Esta consideração poderia viabilizar a implementação de uma abordagem mais robusta de sustentabilidade em empreendimentos, ao incluir estratégias e tecnologias que, na 
visão corrente, são descartadas de imediato. A maior parte dos investimentos em real estate não considera aspectos sociais ou ambientais relacionados ao empreendimento, uma vez que estão focados no retorno econômico puro (LÜTZKENDORF; LORENZ, 2005).

Os custos que compõem a fase de utilização de uma edificação, quando estendidos a um período de vida que pode chegar a horizontes longínquos, representam a maior parte do custo total do empreendimento. Johnson (1990) concluiu que custos referentes à construção de um edifício, cuja vida útil é de 40 anos, representam apenas $18 \%$ do custo total do ciclo de vida e que a falsa percepção - de serem mais elevados os custos iniciais - ocorre dado o montante das quantias desembolsado num relativo curto período de tempo, isto é durante a fase de construção.

As metodologias de avaliação ambiental de edificações, como a norte-americana Leadership in Energy and Environmental Design - LEEDTM, procuram fazer o link entre o desempenho ambiental de empreendimentos e seus respectivos custos ao longo do ciclo de vida, uma vez que as possíveis soluções e tecnologias necessárias a uma edificação certificada só se viabilizam quando se entende os benefícios e retornos financeiros dentro de um período de tempo que seja aceitável para os investidores.

\subsection{Objetivos e justificativas}

Este trabalho tem o objetivo geral de contribuir para o entendimento da aplicação da certificação ambiental de edifícios norte-americana LEEDTM e do conceito de custos no ciclo de vida em empreendimentos mais sustentáveis no Brasil. Neste sentido, foi estudada a aplicação desta metodologia em empreendimentos brasileiros, procurando identificar as facilidades e restrições quando da sua utilização na realidade brasileira.

O estudo da aplicabilidade do LEEDTM no contexto brasileiro faz-se necessário uma vez que esta metodologia é uma das mais aceitas comercialmente em termos internacionais; é uma das duas certificações atualmente disponíveis no mercado brasileiro e que norteia a maior parte das edificações atualmente interessadas em certificação ambiental no Brasil. Apesar de desenhado a partir de tradições e padrões construtivos dos Estados Unidos, e de normas e legislações elaboradas naquele país, este método está sendo utilizado no contexto brasileiro tal como originalmente desenvolvido para a realidade norte-americana.

Considerando que sustentabilidade é um conceito de longo prazo e tendo o intuito de se produzir edifícios mais sustentáveis com desempenho igual ou superior ao das edificações 
convencionais, a análise de custos no ciclo de vida compõe o grupo das técnicas de gerenciamento e controle de custos - juntamente com processo de melhoria contínua de valor, engenharia de valor verde, projeto e construção enxuta (JACOMIT; SILVA; GRANJA, 2009; LAPINSKI; HORMAN; RILEY, 2006) - que, ao lado- do processo de projeto integrado PPI (COLE; STERNER, 2000; SILVA, FIGUEIREDO, 2008; 7 GROUP AND REED, 2009), constitui uma das duas grandes apostas para demonstração não só de viabilidade, mas também de que construções com metas de sustentabilidade não implicam necessariamente em aumento de custos em relação a construções convencionais, podendo, se bem integrados ao processo de entrega do empreendimento, inclusive chegar a redução de custos.

\section{Sumário metodológico}

Em alinhamento aos objetivos do trabalho, de discussão sobre a aplicação do LEEDTM em empreendimentos que buscam esta certificação dentro da realidade do mercado da construção civil brasileiro, identificando facilidades e restrições de sua aplicabilidade, 0 desenvolvimento do estudo aplicado foi dividido em duas grandes fases: (i) determinação da freqüência de atendimento de cada ponto, após normalização dos dados segundo a estrutura do LEEDTM NC 2.2 e (ii) análise qualitativa das dificuldades existentes para atendimento ao LEEDTM nos EUA e no Brasil.

\subsection{Determinação da freqüência de atendimento de cada ponto LEEDTM}

Primeiramente, foram analisados, ponto a ponto, os dados dos relatórios existentes Matthiessen e Morris (2004) e Cryer et al. (2006) quanto à freqüência do cumprimento dos requisitos LEEDTM em empreendimentos norte-americanos. Pela grande amostragem constante nos relatórios de referência (296 projetos no total), assumiu-se que quanto maior a freqüência de busca/obtenção de um ponto, maior a facilidade do seu atendimento, seja por baixo custo, fácil implementação ou outra razão. Esta fase teve por finalidade entender se as facilidades e limitações quanto à aplicação destes requisitos são intrínsecos ao mercado da construção civil em si, face às inovações de soluções de projetos e tecnológicas a serem buscadas para a certificação, ou se são acentuados ou atenuados em função de características da indústria da construção civil brasileira, uma vez que a aplicação da metodologia LEEDTM é baseada em normas e legislações dos EUA, país com características e necessidades diferentes das encontradas no Brasil. 
A freqüência de atendimento de cada crédito foi separada em quartos, sendo considerados como "muito freqüentes" (MF), os requisitos com freqüência de ocorrência superior a $75 \%$; como "freqüentes" $(F)$, os requisitos com freqüência entre 50\% e 75\%; como "pouco freqüentes" (PF), os requisitos com freqüência entre $25 \%$ e $50 \%$; e como "raros" (R), aqueles cuja freqüência tenha sido inferior a $25 \%$.

Com os resultados obtidos, foram elaboradas duas matrizes comparativas (PARDINI, 2009): primeira delas, reunindo resultados da freqüência do alcance de cada um dos créditos, a partir de Matthiessen e Morris (2004) e de Cryer et al. (2006); e a segunda, comparando o resultado da primeira matriz com a obtenção dos pontos referentes a cada requisito para os dois empreendimentos nacionais estudados.

Em Matthiessen e Morris (2004), a freqüência de cada requisito é apresentada para cada nível de certificação LEEDTM, sendo que as edificações nos níveis ouro e platina apresentam-se agrupadas. Apesar de não explicitado no texto, presumiu-se, a partir de sua data de publicação, que este traga informações baseadas na versão 2.1 do LEEDTM NC. Já os dados apresentados por Cryer et al. (2006) são referentes à versão LEEDTM 2.2, e a freqüência de obtenção de cada ponto é apresentada nos quatro níveis de certificação LEEDTM (certificado, prata, ouro e platina).

Para reproduzir o agrupamento feito por Matthiessen e Morris (2004) e tornar seus dados comparáveis com os de Cryer et al. (2006), projetos nos níveis Ouro (58 empreendimentos) e Platina (7 empreendimentos) foram somados através de média ponderada do atendimento dos requisitos. Para procedimento detalhado, ver Pardini (2009).

Finalmente, buscando efetuar uma análise dos requisitos atendidos e verificar se haveria um padrão de atendimento entre os pontos obtidos/pleiteados por estes empreendimentos e os casos norte-americanos registrados nos relatórios de referência, uma segunda matriz foi elaborada (PARDINI, 2009), comparando os resultados norte-americanos com os dados obtidos nos checklists enviados ao USGBC para os processos de certificação LEEDTM dos dois estudos de casos nacionais examinados neste estudo.

\subsection{Análise qualitativa das dificuldades existentes para atendimento ao LEEDTM nos EUA e no Brasil}

A análise qualitativa das dificuldades existentes quando da implementação das estratégias "verdes" para atendimento aos requisitos LEEDTM nos EUA e no Brasil foi feita com base em: 


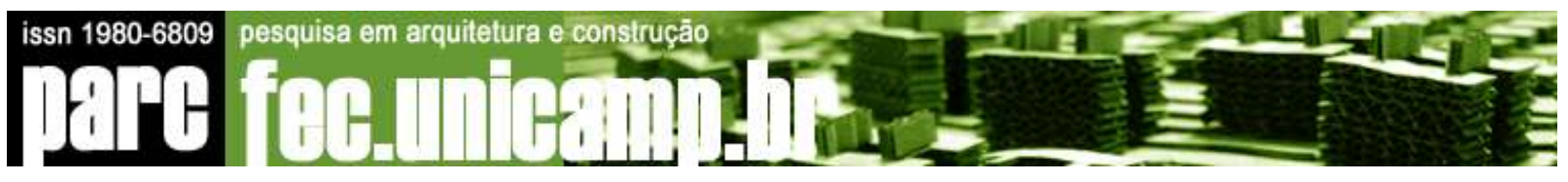

Resultado obtido para o item 2.1, em comparação com Matthiessen e Morris (2004) e Cryer et al. (2006), quanto à freqüência de obtenção de cada ponto LEEDTM;

Langdon (2007), documento descritivo que posiciona os requisitos LEEDTM no contexto dos EUA;

Análise documental, principalmente os relatórios de sustentabilidade no decorrer das obras para o processo de certificação, elaborados pelas empresas de consultoria para determinação dos pontos que estão sendo pleiteados em cada empreendimento;

Pesquisa de percepção junto a agentes envolvidos nos estudos de caso nacionais, tanto da construtora quanto da incorporadora. Foram entrevistados (1) o diretor dos contratos, responsável pelos dois empreendimentos, (2) os gerentes de cada projeto e (3) membros da equipe de obra da empresa incorporadora responsável pelo desenvolvimento dos dois empreendimentos.

\subsection{Apresentação dos estudos de casos}

Para posicionamento da discussão no contexto brasileiro, foram analisados dois edifícios comerciais de escritórios com padrão de acabamento de alta qualidade, classificados pela respectiva incorporadora como Triple A (Quadro 1). A escolha destes dois empreendimentos foi feita por se tratar de dois dos primeiros empreendimentos buscando a certificação LEEDTM no Brasil, idealizados pela mesma incorporadora, e executados pela mesma construtora.

Por ocasião deste trabalho, ambos estavam em construção e em busca da certificação LEEDTM Core \& Shell 2.0 (nível ouro), apropriada para edifícios comerciais onde o investidor local vende as áreas internas dos pavimentos, não sendo responsável pelos acabamentos internos dos andares, transferindo aos futuros usuários esta ação. Vale ressaltar que as diferenças entre o LEEDTM NC para novas construções e o LEEDTM Core \& Shell são pequenas, e não prejudicam a comparação sugerida. 


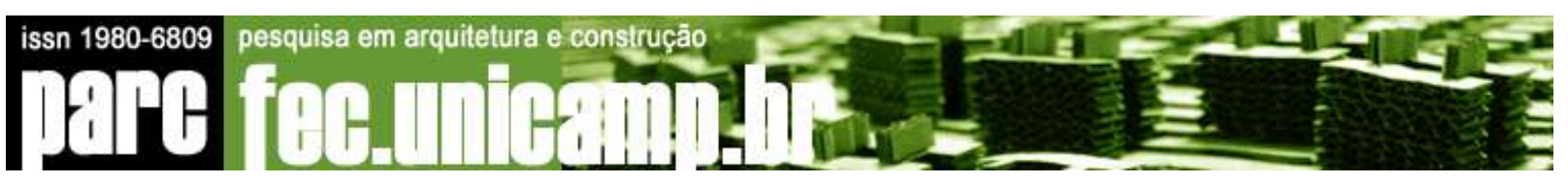

Quadro 1 - Descrição sumarizada dos Estudos de Casos A e B.

\begin{tabular}{|l|l|l|}
\hline DESCRIÇÃO & CASO A & CASO B \\
\hline Local: & São Paulo - SP & Rio de Janeiro - RJ \\
\hline Área do terreno (Fase I): & $9.400 \mathrm{~m}^{2}$ & $4.250 \mathrm{~m}^{2}$ \\
\hline $\begin{array}{l}\text { Área do terreno (Fases I e } \\
\text { II): }\end{array}$ & $37.730 \mathrm{~m}^{2}$ & $8.500 \mathrm{~m}^{2}$ \\
\hline Área construída: & $59.000 \mathrm{~m}^{2}$ & $\begin{array}{l}59.000 \mathrm{~m}^{2} \text { Bloco } 1+25.000 \text { Bloco } \\
\text { Garagem }\end{array}$ \\
\hline Área Locável: & $29.000 \mathrm{~m}^{2}$ & $51.000 \mathrm{~m}^{2}$ \\
\hline Pavimentos: & $\begin{array}{l}03 \text { subsolos, pavimento térreo, } \\
\text { mezzanino, 16 pavimentos tipo, } \\
02 \text { pavimentos mecânicos, } \\
\text { cobertura e heliponto }\end{array}$ & $\begin{array}{l}05 \text { subsolos, pavimento térreo, } \\
\text { mezzanino, 35 pavimentos tipo, } 02 \\
\text { pavimentos mecânicos, cobertura e } \\
\text { heliponto }\end{array}$ \\
\hline Elevadores: & 12 unidades & 22 unidades \\
\hline Vagas de estacionamento: & 3.100 & $\begin{array}{l}800 \text { em prédio garagem com } 10 \\
\text { pavimentos }\end{array}$ \\
\hline Área pavimentos: & De 1.600 a 2.000 m² & $1.600 \mathrm{~m}^{2}$ \\
\hline
\end{tabular}

Tais estudos de casos configuram, neste trabalho, a base para aferir os pontos fortes e as limitações encontradas na estratégia de projeto utilizada na busca do atendimento aos requisitos LEEDTM quando do processo de certificação dos empreendimentos. Por meio dos resultados encontrados, é possível entender se as dificuldades e facilidades da aplicação desta metodologia se restringem ao mercado brasileiro ou são simplesmente decorrentes de exigências superiores de desempenho ambiental, independentemente do país que busca tal certificação.

\section{Discussão de resultados}

Os resultados obtidos indicam que, nos EUA, dos 69 pontos possíveis, 15 deles (22\%) são obtidos com muita freqüência, sugerindo implementação facilitada por proximidade de prática típica ou regulatória, alta custo-efetividade, menores impactos no custo inicial/global, entre outros; enquanto 18 pontos (26\%) são conquistados freqüentemente; 11 pontos (16\%) são pouco freqüentes, e os 25 pontos restantes (36\%) aparecem raramente nos projetos analisados nos dois relatórios, indicando prováveis dificuldades para seu atendimento.

Neste resultado não estão computadas as dificuldades encontradas para cumprir os prérequisitos, uma vez que são obrigatórios, mas cabe ressaltar que podem se apresentar como desafios importantes na realidade brasileira. 


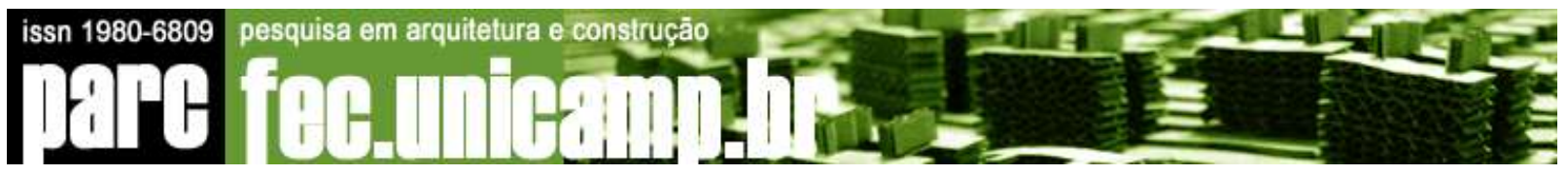

A análise comparativa, detalhada ponto-a-ponto, do grau de dificuldade de atendimento aos requisitos LEEDTM no contexto original dos EUA e no Brasil está sintetizada em Pardini, 2009.

\section{Discussão}

Os resultados obtidos indicam que, nos EUA, 48\% dos 69 pontos disponíveis no sistema são obtidos com freqüência alta ou muito alta. Já para os dois estudos de casos nacionais, observou-se que 27 pontos (39\%) foram obtidos nos dois empreendimentos, sugerindo maior facilidade ou viabilidade de implementação dos aspectos a eles relacionados. Tais pontos distribuem-se no quatro grupos de freqüência de ocorrência identificados a partir dos relatórios-base, isto é: os pontos obtidos no Brasil incluem tanto aqueles muito freqüentes (como envolvimento de profissional LEED e dois pontos de inovação em projeto/superação de desempenho) ou freqüentes no contexto americano, quanto pontos pouco freqüentes ou raros (como os dois pontos restantes de inovação em projeto/superação de desempenho) nos Estados Unidos.

Na categoria Terrenos Sustentáveis, observou-se alinhamento claro entre os pontos obtidos no Brasil e aqueles mais freqüentemente alcançados nos Estados Unidos. Esta foi a categoria em que os dois projetos mais se aproximaram de $100 \%$ de atendimento dos pontos disponíveis ( $86 \%$ e $71 \%$ ), exceto basicamente pelos pontos de proteção e recuperação de habitat em meio urbano (nos dois casos), e de tratamento de água pluvial e recuperação de sitio contaminado (Caso B).

$\mathrm{Na}$ categoria Uso racional da água, novamente observou-se alinhamento entre as distribuições de pontos obtidos no Brasil (67\% de atendimento dos pontos disponíveis nos dois casos) e nos Estados Unidos, e confirmação da dificuldade ou não priorização da obtenção dos dois pontos classificados como raramente obtidos (tecnologias inovadoras para reutilização de águas servidas).

$\mathrm{Na}$ categoria Energia e Atmosfera, apesar do perfil de desempenho variar entre os dois casos, percebe-se que o número de pontos obtidos é apenas ligeiramente inferior à média apontada nos relatórios-base, sendo que o Caso A obteve, inclusive, cerca da metade dos pontos classificados como raramente obtidos nos Estados Unidos: 5 pontos extras de desempenho otimizado de energia (35\% de redução do consumo de energia, quando a situação típica é a obtenção de apenas 3, correspondentes a 17,5\% de redução). 
$\mathrm{Na}$ categoria Materiais e Recursos, os casos nacionais mostraram-se aderentes ao perfil típico de distribuição de freqüência de atendimento de pontos nos Estados Unidos. Já na categoria Qualidade do Ambiente Interno, de modo geral os edifícios brasileiros saíram-se pior (em termos de número de pontos alcançados) que a média apresentada nos relatóriosbase.

\subsection{Lições aprendidas no contexto brasileiro}

O presente estudo mostrou que alcançar a certificação LEEDTM pode não ser uma tarefa fácil e, diga-se de passagem, nem deveria ser, considerando que o objetivo principal das certificações em geral é prover distinção de práticas de mercado e que o patamar de sustentabilidade do setor da construção nacional ainda tem muito a se desenvolver neste aspecto. No entanto, vale lembrar que a razão pela qual o LEEDTM foi criado era a motivação e a aceleração do desenvolvimento de práticas ambientais e, para tanto, 0 consenso da metodologia foi baseado em padrões e normas vigentes no país de origem EUA. Portanto, ainda que naquele país, atender aos seus pré-requisitos e créditos pressupõe esforço e provoca uma reflexão sobre os processos e tecnologias disponíveis e as lacunas identificadas para elevação contínua do desempenho ambiental de empreendimentos.

A pesquisa de percepção junto a agentes envolvidos na construção e incorporação dos dois estudos de casos (PARDINI, 2009), combinada à análise da documentação para certificação dos empreendimentos, mostrou que, mesmo em centros avançados da construção civil brasileira, como nos casos estudados, o mercado ainda não está preparado para os "selos verdes" internacionais. Muitas empresas ainda desconhecem conceitualmente as certificações e todas as empresas pioneiras no assunto (incorporadoras, construtoras e consultorias) encontram-se em plena curva de aprendizado. Diferentemente do observado no exterior, nos processos de certificação no Brasil, pela falta de profissionais aptos a tratarem da sustentabilidade com a exigência requerida para se obter uma certificação LEEDTM nas empresas incorporadoras e construtoras, os consultores especializados assumem um papel fundamental, uma vez que são, hoje, os profissionais especificamente dedicados a buscar soluções, orientar e controlar os processos para que a certificação seja facilitada.

Se, nos EUA, aplicar certificação implica em melhorias incrementais de boas práticas, já no Brasil, significa, em muitas vezes, saltar da completa ausência de referência para o atendimento de normas americanas e, freqüentemente, estranhas aos profissionais locais, e 
presentes não só em pontos, mas também em pré-requisitos do sistema de certificação. Isto muitas vezes implica num salto demasiadamente alto quando estão em questão hábitos e práticas vigentes, tecnologias e materiais disponíveis no mercado e até mesmo qualificação exigida dos profissionais, o que inclui as empresas de consultoria especializadas hoje atuantes neste mercado. Muitos requisitos e pré-requisitos contidos no LEEDTM fogem, e muito, às práticas brasileiras de mercado e, para a busca de uma certificação, bem como a aplicação de práticas mais sustentáveis na execução de edifícios, faz-se necessária a adequação de toda a cadeia e agentes da construção civil. Esta afirmação pôde ser observada tanto nos estudos de caso aqui realizados, quanto nas respostas aos questionários enviados por Pardini (2009) às maiores incorporadoras atuantes no Estado de São Paulo - maior mercado da construção civil brasileira.

Para alguns créditos do LEEDTM, o atendimento não é resultado de estratégias sustentáveis, mas sim uma casualidade, pois a grande maioria das decisões está vinculada à geração de lucratividade às empresas incorporadoras. Este é o caso notável de pontos da categoria Terrenos Sustentáveis (SS), como por exemplo, aqueles referentes à escolha do terreno; à área urbana ocupada; à recuperação de áreas degradadas e ainda à facilidade de acesso ao transportes público, em que o atendimento - ou não - ocorre apenas quando as características do terreno escolhido - tipicamente em função de parâmetros de mercado coincidem com as condições requeridas pelo sistema de certificação. Apesar de ideais, são extremamente raras - principalmente em estágio inicial de adesão a um sistema de certificação - as oportunidades para intervenção na seleção de áreas dirigida por metas de certificação ambiental.

Em qualquer economia, os governos e suas agências constituem um poderoso impulsionador de tendências. Seja por meio de incentivos fiscais ou da produção de marcos regulatórios que estabeleçam requisitos mínimos de sustentabilidade para edificações, insumos e componentes, o poder público é capaz de movimentar toda a cadeia produtiva da construção e promover a criação de práticas sustentáveis como rotina, seja ao lançar mão de seu papel como grande comprador ou liderando pelo exemplo em suas próprias instalações. Resgatando a situação hipotética recém exposta, incentivos fiscais decorrentes da opção por um terreno contaminado, por exemplo, bem como da comprovação de práticas mais sustentáveis, seriam um grande apelo para investidores e incorporadores construírem empreendimentos de melhor desempenho ambiental e com benefícios à sociedade. 


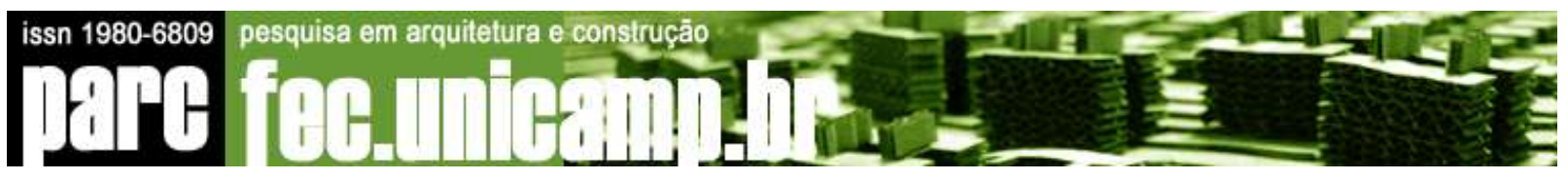

\subsection{Mudanças de paradigmas para viabilizar sustentabilidade}

O assunto sustentabilidade na construção civil, apesar de não ser recente, é ainda incipiente em vários países. Se, por um lado, a difícil mensuração dos benefícios ainda causa ceticismo, por outro, não há como refutar o reconhecimento e ganhos em mídia com fortalecimento da imagem da marca e até mesmo em competitividade atrelados a execução destas edificações.

No Brasil, este movimento começou a dar sinais com mais ênfase nos últimos dois ou três anos. O conhecimento sobre as edificações mais sustentáveis ainda é superficial, mesmo numa amostra significativa de empresas importantes, como a considerada na pesquisa de Pardini (2009), que confirmou que a percepção no país de que estas edificações têm um custo inicial maior é real, porém ainda embasada em pouco conhecimento.

Falta a percepção de que, uma parcela importante destes custo resulta, a exemplo do aprendizado de qualquer coisa nova, das dificuldades relacionadas à mudança de procedimentos e abordagens correntes para se atender ao desafio de obter resultados de alguma maneira superiores. Mas, provavelmente, o principal obstáculo prático para consideração de benefícios durante a etapa de uso e operação são os chamados incentivos divididos, já que o agente que faz o investimento (investidor/incorporador/construtor) não necessariamente é o agente que se beneficia (locador/proprietário final).

A pesquisa realizada complementarmente por Pardini (2009) também corroborou com esta afirmação, e constatou que, no Brasil, ainda não se entende realmente os conceitos de custos ao longo do ciclo de vida das edificações, e, conseqüentemente, não se consegue vislumbrar de que maneira tais conhecimentos seriam úteis economicamente. A percepção geral dos entrevistados ratificou que os benefícios são percebidos explicitamente apenas para os investidores-usuários e para os investidores-patrimonialistas, que coletam diretamente as economias decorrentes de um melhor projeto. Para os demais investidores, custos de operação e manutenção ainda pertencem a quem compra ou loca as unidades do empreendimento.

No entanto, sustentabilidade é um conceito de longo prazo, que jamais poderá ser completamente implementado se sua viabilidade continuar sendo definida por visão e indicadores de curto prazo. A transição do estágio demonstrativo atual para o de transformação irreversível de mercado demanda uma mudança profunda de paradigma dos critérios que dirigem viabilidade de empreendimentos (SILVA, 2009). 
Entender os custos e receitas de uma edificação e considerá-los na fase de estudo de viabilidade, sob a ótica do seu ciclo de vida, implica em ir além dos métodos tradicionais de análise e considerar um fluxo que contenha não só investimentos iniciais e receitas provenientes da comercialização e/ou locação de unidades, mas também que contemple custos de operação e uso do edifício e destas unidades. Edificações com estratégias claras de sustentabilidade, podem demandar um investimento maior, que, se bem aplicado, invariavelmente resultará em um melhor desempenho. Os benefícios são tangíveis, independentemente da discussão sobre quem paga a conta da melhoria de desempenho.

Para ir além dos ganhos intangíveis, como a formação de uma boa imagem da marca da incorporadora ou construtora no mercado, a atração de multinacionais para estes empreendimentos e os ganhos em mídia gratuita, principais motivações registradas por Pardini (2009), é necessário abandonar a zona de conforto representada pela prática tradicional e explorar conceitos inovadores como:

- Inserção do conceito da análise de custos ao longo do ciclo de vida no processo de decisão (Silva, 2007) e até mesmo como critério de decisão; permitindo que os ganhos sejam efetivamente convertidos em lucro, pelo incremento no valor de locação ou venda das unidades, por meio da comprovação e garantia de um condomínio menor ao longo da vida útil do empreendimento;

- União de departamentos de compras e manutenção dentro de uma mesma organização, para que os custos iniciais de um empreendimento sejam vistos como investimentos de longo prazo e não apenas despesas. Neste conceito, a medida do sucesso de uma aquisição deve ser a economia gerada pelo melhor desempenho do projeto, equipamentos e sistemas propostos;

- Remuneração dos projetistas por desempenho (contratos de incentivo), onde seria garantida a economia de recursos na fase de projetos e além do valor de projetos corriqueiramente pago, seria atrelado um valor mensal a receber por um prazo estabelecido, em função das economias projetadas, o que permitiria não só incentivo a projetistas, mas a possibilidade de prover retorno a investidores/incorporadores/construtores para recuperação (ou superação) do investimento inicial (Silva, 2009a);

- Remuneração da equipe de gestão de facilidades por desempenho (contratos de incentivo), para garantir ou superar o desempenho de projeto ao longo de toda a vida útil da edificação, de forma semelhante à descrita acima (Silva, 2009b); 
- Inovação na estrutura de locação, de modo a alinhar objetivos e transferir ou compartilhar riscos e benefícios entre locatários e locadores, de modo que o aluguel seja percebido como investimento e não somente despesa (Silva, 2009a).

\section{Considerações finais}

O presente estudo mostrou que alcançar a certificação LEEDTM pode não ser uma tarefa fácil em um setor da construção que ainda tem muito espaço para desenvolvimento no campo de sustentabilidade.

Apesar dos projetos estudados não representarem uma amostra representativa da construção nacional, eles demonstram que, mesmo em situações das mais propícias para candidatura a certificação, e em centros avançados da construção civil brasileira, o mercado ainda não está adequadamente preparado para os "selos verdes" internacionais e ainda existem grandes obstáculos a serem superados.

As limitações e facilidades no atendimento dos requisitos LEEDTM no Brasil variam caso a caso, dependendo de vários fatores, como: Localização do empreendimento; Localização geográfica brasileira; Padrão de acabamento e sofisticação de projetos; Custo planejado para o empreendimento. Os dos estudos de casos aqui analisados encontravam-se numa situação privilegiada para buscar a certificação, por (1) estarem localizados nas duas maiores cidades do Brasil, facilitando a aquisição de materiais, tecnologias e profissionais adequados; o Caso A, em particular, localizado em São Paulo, estado que fornece todas as condições para que a resolução CONAMA 307 seja cumprido, e conta com opções para a disposição apropriada de resíduos; (2) serem de grande porte e valor; e (3) partirem conceitualmente de projetos norteamericanos. Além disso, pela visibilidade na mídia e por serem identificados como dois dos primeiros empreendimentos brasileiros a buscarem a certificação LEEDTM, todos os projetistas envolvidos consideraram o trabalho excedente necessário para a adequação aos requisitos LEEDTM dos projetos convencionalmente concebidos como investimento em conhecimento.

As lições aprendidas com os projetos brasileiros analisados indicam que:

- $\quad$ Consultores são necessários, no entanto, eles também estão em fase de aprendizado;

- Muitos materiais e tecnologias são desconhecidos pelo mercado e os preços nem sempre são competitivos;

- $\quad$ re-trabalho em projetos foi necessário para a adequação aos objetivos pretendidos; e 


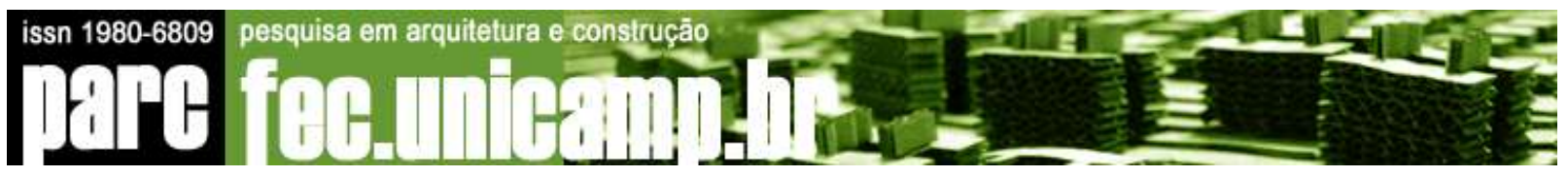

- Apesar de isto não ter ocorrido nos Estudos de Casos analisados, são necessários atenção e esforço redobrados para que o prazo do projeto não seja comprometido pelas dificuldades inerentes a um novo processo.

Finalmente, associada às novas tecnologias e às inovações de um modo geral, há uma curva de aprendizado com duração de cerca de três anos, estimada com base na experiência das autoras deste trabalho e na análise dos processos de adesão a certificações observados em outros países.

Certificar um empreendimento é um processo e, como tal, para ser validado, requer documentação e comprovação do atendimento aos requisitos solicitados. Pelo menos nos primeiros empreendimentos, durante o período de curva de aprendizado, buscar a certificação implica em mudança de rotina, comprometimento e acréscimo de trabalho para todos os envolvidos com o empreendimento, desde os arquitetos e projetistas até mesmo aos fornecedores e subcontratados para execução dos serviços.

Apesar de todas as limitações do LEEDTM e de sua aplicação em contextos diferentes do seu original, a entrada desta metodologia no Brasil traz consigo uma nova forma de se enxergar os impactos gerados às pessoas e ao meio ambiente, pelo produto da construção civil, abrindo assim a discussão para assuntos antes nunca abordados. Certificações, iniciativas voluntárias e instrumentos de market pull (incentivos fiscais, descontos, liderança pelo setor público) possuem o importante papel de mola propulsora da transformação do mercado da construção civil na busca da sustentabilidade. É inegável o seu papel na criação de oportunidades para uma grande quebra de paradigmas no mercado da construção civil brasileira. O que não se pode perder de vista é que as certificações pressupõem uma base anterior - composta por P\&D e transferência de conhecimento e tecnologia ao mercado - para que possam se desenvolver plenamente. O que se deve evitar no Brasil é que a ansiedade pela busca de certificação, não precedida pela necessária preparação do mercado, resulte no risco de fragilizar o papel transformador das certificações, devido à queima das etapas de base. 


\section{Referências}

7 GROUP AND REED, W. The Integrative Design Guide to green building: redefining the practice of sustainability. Hoboken, NJ: John Willey and Sons, 2009.

COLE, R. J.; STERNER, E. Reconciling theory and practice of life-cycle costing. Building Research \& Information, London, v. 28, p. 368-375, 2000.

CRYER, B.; FELDER, J.; MATTHEWS, R.; PETTIGREW, M.; OKRENT, B. Evaluating the Diffusion of Green Building Practices. Los Angeles: UCLA Anderson School of Management, 2006. 82 p. Disponível em: < http://www.personal.anderson.ucla.edu/charles.corbett/papers/diffusion_green_building .pdf>.

DAVIES, R. Green Value, Green Building, growing assets. Report 2005. Disponível em: <http://www.rics.org/NR/rdonlyres/93B20864-E89E-4641-AB11028387737058/0/GreenValueReport.pdf>. Acesso em: Nov. 2007.

JACOMIT, A.M.; GRANJA, A.D.; GOMES (SILVA), V.G. Reflexões sobre o uso de custeiometa na concepção de empreendimentos sustentáveis. In: VI SIBRAGEC - Simpósio Brasileiro de Gestão da Economia da Construção. Anais... João Pessoa - PB: ANTAC, 21 a 23 de outubro de 2009.

JOHNSON, R., Life-cycle costing. In: The economics of building. Hoboken, NJ: John Willey and Sons, 1990. Chapter 167, p. 213-231.

DAVIS LANGDON. Costing of green revisited - Reexamining the Feasibility and Cost Impact of Sustainable Design in the Light of Increased Market Adoption. 2007. 25 p. Disponível em: <http://www.davislangdon.com/upload/images/publications/USA/The\%20Cost\%20of\%2 0Green\%20Revisited.pdf>. Acesso em Nov. 2007.

Kats, G. 2003. The cost and financial benefits of green buildings: A Report to California's Sustainable Building Task Force. Sacramento, CA: Sustainable Building Task Force. Disponível em: http://www.calrecycle.ca.gov/greenbuilding/design/costbenefit/report.pdf>. Acesso em Nov. 2007.

Kats, G. 2006. Greening America's schools - Costs and benefits. A Capital-e report. Washington D.C.: Capital-E. 24 p. Disponível em: < http://www.usgbc.org/ShowFile.aspx?DocumentID=2908>. Acesso em Nov. 2007. 
LAPINSKI, A. R.; HORMAN, M.J ; RILEY, D. R. Lean Processes for Sustainable Project Delivery. Journal of Construction Engineering and Management ASCE, p. 1083 - 1091, October 2006.

LÜTZKENDORF, T.; LORENZ, D. Sustainable property investment: valuing sustainable buildings through property performance assessment. Building Research \& Information, S.I., v. 33, n 3, p. 212-234, 2005.

MELAVER, M.; PHYLLIS, M. The green bottom line: the real cost of sustainable building. 1 ed. Estados Unidos: The McGraw Hill Companies, 2009. 359 p.

MATTHIESSEN, L.F.; MORRIS, P. Costing Green: A Comprehensive Cost Database and Budgeting Methodology. Los Angeles: Davis Langdon, 2004. 27 p. Disponível em: < http://www.davislangdon.com/upload/images/publications/USA/2004\%20Costing\%20G reen\%20Comprehensive\%20Cost\%20Database.pdf>. Acesso em Nov. 2007.

NORNES, D. Use of life cycle costing in the U.S. green building industry. Dissertation (Master of Science). Fort Collins, Colorado: Department of Construction Management, Colorado State University. 2005.

PARDINI, A. F. Contribuição ao entendimento da aplicação da certificação LEEDTM e do conceito de custos no ciclo de vida em empreendimentos mais sustentáveis no Brasil. Dissertação de Mestrado. Campinas: Universidade Estadual de Campinas, Faculdade de Engenharia Civil, Arquitetura e Urbanismo. 2009. 210 p.

SILVA, V. G.; FIGUEIREDO, F.G. Integrated design and the conventional practice: reflections on the environmental performance of one case study in Brazil. In: 2008 World Sustainable Building Conference, Melbourne, Australia. Proceedings... Melbourne: CSIRO, 2008. v. 2. p. 661-666.

SILVA, V. G. Certificação ambiental de edifícios: o que realmente importa? In: 10 anos de atividade da AsBEA regional Paraná, Curitiba - PR, 08 de maio de 2007. (notas de palestra convidada).

SILVA, V. G. Viabilizando empreendimentos mais sustentáveis: Projeto integrado, modelo de custos e outras cinco inovações. In: 10. Seminário Sustentabilidade e Facilities. Abrafac/CBCS, São Paulo - SP, 27 de maio de 2009a. (notas de palestra convidada).

SILVA, V. G. Gestão Sustentável de Facilidades. In: 9a. Conferência Internacional da Latin American Real State Society, São Paulo - SP, 14 de outubro de 2009b. (notas de palestra convidada). 